\title{
"Open" Philosophy or Down the Rabbit Hole?
}

\author{
Wayne Bowman
}

In this essay, I challenge the open-closed dualism at the heart of Allsup's project and question the very possibility of an "open" philosophy. I propose an account of music, musical instruction, and philosophy as ethically guided practices, discussing a number of practical and philosophical consequences that follow from such a view.

Keywords: ethics, practice, praxis, philosophy, music education

"I don't know what you mean by 'glory,' " Alice said.

Humpty Dumpty smiled contemptuously. "Of course you don't-till I tell you. I meant 'there's a nice knock-down argument for you!'

"But 'glory' doesn't mean 'a nice knock-down argument'," Alice objected.

"When $I$ use a word," Humpty Dumpty said, in rather a scornful tone, "it means just what I choose it to mean-neither more nor less."

"The question is," said Alice, "whether you can make words mean so many different things."

"The question is," said Humpty Dumpty, "which is to be master-that's all."

-Lewis Carroll, Through the Looking Glass

$\mathrm{I}$

n Remixing the Classroom Randall Allsup advances what he calls an "open philosophy of music education.” His arguments are clearly heart felt, and with many of them I am in full agreement, having urged for most of my professional career that there is a pressing need for more diversity and inclusiveness in North American music education; that the status quo has become all too comfortable and comforting; that music educators need to provide students with

(C) Wayne Bowman 2017. The content of this article is the sole responsibility of the author. The ACT Journal and the Mayday Group are not liable for any legal actions that may arise involving the article's content, including, but not limited to, copyright infringement. 
instruction that is far more engaging, useful, practical, and durable; that presentational and performance-based musical practices should be balanced with opportunities that are participatory and "amateur"; that the profession needs to develop more critical awareness of the ways power relations operate within musical and instructional practices; that questions, curiosity, imagination, and creativity need to become much higher instructional priorities; and that technical, formulaic, rule-governed instruction threatens to compromise many of music education's most humanly significant benefits. On points like these it would appear we are largely in agreement.

However, on many of Allsup's fundamental assumptions-the principles and hypotheses that constitute the foundation for his positions-I'm afraid we are very far apart. In the concluding chapter of the Oxford Handbook of Philosophy in Music Education, ${ }^{1}$ Frega and I commented that broader involvements represent an important potential advance for music education philosophy. On the other hand, we cautioned, the trend toward greater inclusiveness introduces more divergent assumptions as to what philosophy means and how its success should be gauged. And Humpty Dumpty's claims notwithstanding, "philosophy" can't mean just whatever anyone wants it to mean. There is, Frega and I concluded, an "urgent need for renewed clarity about what the philosophical process involves" (Bowman and Frega 2012, 495): a need to consider very carefully what distinguishes work that informs and advances music educational practice from the rest. Remixing the Classroom illustrates vividly the need for such clarity and such distinctions.

In order to shore up the views and priorities he calls "open," Allsup deploys the rather unseemly strategy of vilifying a substantial body of recent philosophical work-work he misleadingly characterizes as "closed," exclusive, elitist, and performance-based. We've witnessed this before in music education-the inclination to sort "philosophies" into radically opposed camps of "right" and "wrong," where the "rightness" of one view requires the utter and complete destruction of its perceived competition. That strategy has not served either philosophical practice or the profession well in the past, nor does it now. Nor is postmodernism the only-or the best-path to the ends Allsup advocates. Because he is apparently convinced it is, he fails to recognize and enlist potentially important allies in 
his quest to rejuvenate the profession's instructional practices. A missed opportunity.

Since the title of my essay is not just intended rhetorically, let me be clear from the outset. In my view, the book under discussion here is not so much philosophy, as a "muddle" (a word Allsup appears to relish and employs repeatedly)-a "mashup" of rhetorical questions, undefined terms, dubious assertions, oxymorons, and straw men, all wrapped in slippery, postmodern double-speak. If this sounds unfair, consider a few examples, drawn more or less at random from his text. "The world made more perilous," he asserts, "is also more open, and it is moral... It has a moral sense of travel, growth, and adventure: muddled, unholy, with shimmers and lisps and glints of something otherwise, and somewhere else" (128). ${ }^{2}$ Of his ideal, "open" curriculum he says, "the form-the text, its layeringsexists within an unfinished texture of discourses, woven in counterpoint, with and without contradiction, with a depth of meaning and not" (125). It is our job as music educators, he claims, "to reclaim and repurpose the Law; it is our pleasure to riff on words like 'excellence', 'talent', 'creativity', and 'genius' until they lose their oppressive features and give way to something new and beautiful" (88). These are stylishly crafted, evocative assertions; but what they actually meanwhether or in what way they advance our understandings of musical, educational, and philosophical practices or their attendant responsibilities-is far from clear.

"Whatever else one might want to claim for it," we wrote in the Oxford Handbook, "philosophy seeks to further responsible action informed by careful deliberation" (495). It strives "to identify and eliminate confusion, to make action more intelligent, and to make intelligence more active" (496). "Philosophy's prevailing habitus is," in Shusterman's words, "critical analysis," a view Maus eloquently extends: "Philosophy savors precise conceptual distinctions and explicit argumentation... [It] involves commitment to clarity and fairness" (Oxford Handbook, 5). These are matters I will visit often in this essay. They do not appear to be convictions Allsup shares.

An adequate treatment of the many issues that emerge from Allsup's book would require an essay of book length-one that would significantly exceed the parameters of this issue of ACT and demand more time than I have to devote to such a project. I will, however, seek to address a handful of the issues I find particularly philosophically vexatious, including his failure to define terms and 
use them consistently; his gross misrepresentations of "praxial" philosophy (or as I prefer to call it, practice theory); the chasm created by his rigidly binary, "open"/"closed" framework; his contention that expertise, excellence, and musicianship are elitist and oppressive; and his insistence that all musical instruction should be devoted to serving democratic ideals (of one particular kind, in one particular way). Beneath these issues lies a fundamental pair of questions I urge readers to bear in mind: What is philosophy? And, what should the music education profession expect of it?

\section{Overview}

Let's begin with a brief overview of what I take to be the main assumptions of Allsup's project. This is not an easy task, because they present something of a moving target, asserted unconditionally in certain places while more modestly stated, or even contradicted, elsewhere. Although isolated statements may be found that are at odds with my representations here, I will try to describe what appear to be the predominant versions of his arguments.

Allsup's overarching concerns seem to be three in number. First, the creation of teachers who refuse the role of Master (invariably capitalized, and clearly an evil to be avoided). Second, the transformation of music education institutions from replicators of the status quo into vehicles for nurturing growth, flexibility, and continual renewal (an aim with which, stated as it is, no reasonable person could take issue). And third, the endorsement of "aesthetic forms" that "overflow with meaning" (the meanings of "aesthetic," "aesthetic forms," and "overflowing meaning" being matters to which only modest attention is devoted, their purposes apparently being emotive and inspirational rather than explicative). The central concern is thus the pursuit of alternate approaches to "music teacher education" (by which, one eventually infers, Allsup actually means the preparation of school music teachers) and "the practice of teaching music" (xi)"practice" being conspicuously singular and unfortunately undefined.

The first of these three themes has many corollaries, one of the more noteworthy being that "standards" are "Laws" (again, most often capitalized)-nonnegotiable, oppressive, and, apparently largely arbitrary, historical conventions. The enforcement of such Laws falls to a Master, whose mastery is largely politi- 
cal, a function of the power he [sic] is able to wield. Musical and instructional (and similarly, one suspects, philosophical?) expertise, then, functions ideologically, rationalizing the unjustified imposition of subordinate status upon naïve, passive apprentices, cultivating beliefs and habitual action patterns that allow little if any room for personal agency. "The benefits of the Master apprentice relationship," we are told, "come at a human cost," a cost that is "at odds with the values of a democratic society" (11).

The problem from which Allsup's book takes its title follows from the issues just mentioned: the unfortunate predominance in music education of "closed forms": musical-instructional systems built around unacceptably narrow "performance norms and closed standards of expertise" (110); "forms" that are "inherently opposed to popular input," since "the expert is naturally averse to democratic participation" (54). In stark contrast to this, Allsup's “open forms" embrace the ongoing quest for new meanings, inviting us to "break from fixed categories in art and life" (3). These are classic straw man tactics in which a deeply and deliberately flawed position is advanced, to which one's own serves as the obvious and essential remedy. "Closed forms" are thus demons to be exorcised, along with the oppressive instructional approaches they supposedly implicate. The necessary solution to this problem (indeed, it appears, the only viable alternative to closure and its odious Laws) is "openness." Thus he divides music and the music education profession (and again, by extension, its philosophical practitioners) into "us" (the good guys) and "them" (the bad); those whose minds are open and those whose minds are closed; those whose ideas and practices are right and those that are wrong; those whose practices are democratic and those that are autocratic and oppressive; those who are flexible and creative, and those who are mere conformists; those who "make," and those who merely "do." 3 While he claims his "open" approach represents "a vision that would collapse the either-or boundaries that direct most of today's practices" (24), at its heart lies a dualism every bit as vicious and insidious as those he claims to have dissolved. His is a profoundly bifurcated, hierarchical vision in which novelty is inherently good and tradition is villainous. This dichotomy invites readers not only to toss the musical baby out with the bath, but also to summarily dismiss a substantial body of philosophical work that has sought to demonstrate responsibly the crucial roles of tradition and cooperation in many-perhaps most-of the world's musical practices. A substan-

Bowman, Wayne. 2017. "Open Philosophy" or Down the Rabbit Hole? Action, Criticism, and Theory for Music Education 16 (1): 10-37. doi:10.22176/act16.1.10 
tial part of the problem here stems from the dubious assumption that music consists in "forms" (which must be either open or closed) rather than in diverse, flexible, ethically guided human practices: a major issue to which I will return in due course.

This dualism also illustrates what is sometimes called outgroup homogeneity: the tendency to see one's own territory as wonderfully various and multidimensional while others' is monotonous, drably uniform, all the same. ${ }^{4}$ Allsup's "open" approach is rich and variegated while the alternative is all of one cloth: hopelessly "closed," oppressive, and undemocratic. His is an "unholy form of music education" (118) that is "wondering and wandering" (120): a "wondrous and unruly muddle" (33) that "continuously seek[s] renewal, [operating] in a way that is ongoing and provisional" (134). His is a "diversity-affirming classroom" (17), to which the only apparent alternative is a classroom that suppresses diversity through imposition or indoctrination. Outgroup homogeneity is what we encounter in those who claim to dislike classical music (or jazz, or country, or hip-hop, or whatever) because "it all sounds the same"-whereas one's own music, whatever that may be, is wonderfully detailed and wondrously diverse.

"If video killed the radio star, and if the internet killed the video star," claims Allsup, "surely the open-text educator will dethrone the closed-form Master" (68). Its question-begging language aside (clearly, the intrepid "educator" must "dethrone" the old-fashioned, egotistical "Master"), the aim is to discredit apprenticeship approaches to teaching and learning. Not only is his "open" instructional approach more advanced than its outdated counterpart, it is also "much more difficult" (69): "The Master-apprentice model is the easiest way to teach," claims Allsup. "The Master works in a stable domain in which norms are preestablished, expertise is objectively recognized, and ends are measurable and clear-a take-it-or-leave-it learning environment of overwhelming control" (67). In contrast, those who subscribe to Allsup's views-those who share what he calls his "spirit of adventure" (69) are "inquisitive interdisciplinarians" (68), dedicated to using technology to "[open] up spaces that are more cooperative and more socially just" (69).

Thus do straw man tactics and outgroup homogeneity conspire to divide the world of professional music education against itself: into winners and losers, imaginative innovators and old-fashioned, self-serving hacks. "I hereby announce 
the Master's demise," decrees Allsup: "[The Master] must learn to share" (68). ${ }^{5}$ It appears, however, that the same might be said for the "open text educator," who, as described, might as aptly be called an "open form Master."

As indicated earlier, emotional appeals to democracy figure centrally in Allsup's accounts of openness: The Master-apprentice relationship is fundamentally at odds with democratic values, values undermined by the Master's "love of overwhelming control," and by "his desire to control and silence others" (11). While Freirean accounts of pedagogical oppression do offer devastating critiques of authoritarian practices and the ways they work, it is far from clear that all musical practices involving apprenticeship are inherently, invariably, or uniformly oppressive. Nor is it necessarily the case that democracy constitutes the only viable alternative to authoritarian systems. Nor, for that matter, is democracy a uniform entity. Democracy is, rather, a short-hand label we find convenient to apply to a broad and dynamic continuum of practices that range from direct to representative, that balance personal autonomy and obligations in diverse ways, and that navigate the precarious course between freedom and responsibility differently. In Allsup's account, however, democracy is all of one cloth, consisting, it frequently appears, in the state of utter personal autonomy he calls "open"-a state unconstrained by tradition, rules, standards, and their Masterenforcers. ${ }^{6}$ Appealing though these claims to freedom and openness may sound, they are not recognizably democratic. To characterize Allsup's vision as anarchic might be to take things too far, but his idealized notion of unrestrained and unqualified "openness" often veers dangerously close. To teach or make music as if anything and everything were permissible would be irresponsible. And the idea of a purely "open" philosophy is an oxymoron.

While there do exist musical practices (note, practices) that are more open than others, it is hard to imagine any that are utterly open. At the same time, it seems perfectly reasonable to claim that there exist musical practices that flourish and that enhance human flourishing without being utterly and profoundly "open." The orientation Allsup advocates is, I submit, one potentially valid approach to music-making and music teaching among many other valid contenders. His is not the one true path to democracy, in part because "democracy" is itself plural and diverse-richer and more various and more complex than he allows, with cooperation and common purpose figuring among its greatest assets. As 
American politics have demonstrated vividly of late, to misconstrue democracy as a uniform and inherent good, where anything goes and freedom is absolute, can pose a very real danger to something that is in fact intricate, fragile, and all-toocapable of being derailed. Democracy neither requires nor benefits from the kind of unfettered freedom Allsup seems to idealize. It is not utterly "open": it requires constraint, compromise, cooperation, and critically informed historical awareness. True democratic practices (note, practices) require the kind of mutuality in which we acknowledge, look out for, and fairly represent each other out of concern for the good of the collective, and in which traditions are acknowledged as potentially precious assets. These claims are no less true of musical practices. Straw man tactics and the denigration of expertise get us nowhere that is recognizably democratic or musical, in my view. Allsup advances one particular normative ideal as the end to which all musical instruction must be devoted: "The aim of school and university music education...should be openness," he writes (9, my emphasis). Putting all our musical or instructional eggs into a uniform basket called openness or democracy does justice neither to musical practice nor to democracy.

\section{Definitions?}

As this discussion of democracy suggests, many of the points of confusion in Allsup's book stem from his reluctance to define terms and use them consistently, concerns that lie close to the heart of philosophical practice. It raises more immediate, practical questions, too: At whom are the book's "closed form" accusations being leveled? Exactly whose musical, instructional, and philosophical transgressions is this "open philosophy" really intended to redress? As suggested earlier, I eventually reached the conclusion that his primary target consists of those who aspire to teach school music and those charged with preparing them for that role.7 Perhaps the word "classroom" in the book's title should have made that clear. However, if one comes to this book with a more inclusive understanding of what "music education" refers to (say, the act of teaching and learning music, wherever or whenever that may occur), significant confusion may well follow. As indicated, among the book's stated aims is the search for "alternative ways to address university music-teacher education and the practice of teaching

Bowman, Wayne. 2017. "Open Philosophy" or Down the Rabbit Hole? Action, Criticism, and Theory for Music Education 16 (1): 10-37. doi:10.22176/act16.1.10 
music" (xi). However, music teacher education is not the exclusive domain of those concerned to prepare teachers for school classroom instruction, nor are all music education programs designed solely-or even primarily-to prepare teachers for positions in schools. Music education is not school music. What Allsup calls the practice of teaching music is not really singular or uniform, in other words. In fact, very few true "practices" are. The ends to which music teaching is devoted and the situations in which it is intended to occur are, like musical practices themselves, numerous and diverse. Because the master-apprentice approach to instruction is one of Allsup's primary targets, and because he claims that approach is the predominant one in "music education" (undefined), it can be tempting to assume that his criticisms are directed at any and all who teach music, and everyone who presumes to prepare others to teach. That would have to include teachers of "applied music," where the master-apprentice model is pervasive. There exist musical instructional situations and contexts where the development of performing expertise is rightly a central concern, and this, I submit, is one. ${ }^{8}$ Were Allsup's unqualified assertions to be taken literally in those situations ("The aim of ... university music education is not performance expertise... it should be openness" [109]) -if the master-apprentice instructional orientation were discarded in deference to the "openness" Allsup advocates-that instructional practice would not be improved but destroyed. Clearly, it matters what we take the terms "music education" and "music educator" to mean. (I leave here unexplored whether Allsup's characterizations of the master-apprentice approach are universally and necessarily valid. To my way of thinking, it is clear they are not.)

These concerns are not merely technical or academic. Allsup's conviction that performance education is inherently bad disposes him to unfair representations of those whose understandings of music education extend beyond formal schooling or the public school. Neither Christopher Small nor David Elliott, for instance, "[seem] comfortable with the antonymic contradictions of public schooling and its place in a democratic society," claims Allsup. Their philosophical contributions thus "reach their logical conclusions outside of the public school, in community and informal music-making" (23). Even if this were true (which I doubt), it remains to be seen how thinking about music education in these broader, more inclusive ways is supposed to be problematic. Allsup seems determined 
to gauge the efficacy of all musical practices by those applicable to (some, not all) school-based instruction. What is arguably true for school music, he often implies, is necessarily true for all music education-an assumption that fails to acknowledge and honor the rich diversity of musical and instructional practices, forcing them all into roles as democracy's handmaidens. As Frega and I have observed, "What music education means is crucial to determining the range of issues with which music education philosophy is appropriately concerned" (Oxford Handbook, 19). Conflating music education's concerns with those of school music programs, we continue, "neglects many important musical and educational endeavors, significantly narrowing the range of instructional practices to which philosophical inquiry is deemed relevant." While the aims of these respective practices may of course overlap, there are important differences between school music and music education-distinctions Allsup fails to acknowledge because of his preoccupation with openness.

Having turned repeatedly to the question of definitions in Allsup's work, or rather their neglect, I need to touch briefly on what may be one of the book's most glaring omissions. "I have been unseduced," declares Allsup, "by the attempt to define what music is" (139). "I have not been convinced," he continues, "that an adequate definition is possible, or that a provisional definition, once found, could lead to a philosophy of music education." His is a philosophy of music education, in other words, that purports to address processes appropriate to musical instruction, musical learning, and musical experience without benefit of a stance on what music is. A truly remarkable stance for someone claiming to advance a philosophy of music education.

\section{Practices, Practical Knowledge, and Right Action}

I have made a number of passing references to practices in my remarks to this point, and my gravest misgivings about Allsup's work stem from his effort to portray music as a text consisting of open and closed "forms." He makes occasional use of the term "practice" but it is neither used consistently nor is it defined; it seems clear, however, that what he has in mind when he uses this term is not at all what I take it to mean. Since this idea figures centrally in my accounts of music, teaching, educating, philosophizing, and more-and since my appeals to 
practice theory are based on a very specific understanding of the term "practice"-I owe the reader an explanation. Because I have explored this idea from various perspectives in recent years (among them Bowman and Frega 2012; Bowman 2014; Bowman 2015; Bowman 2016), I won't attempt an exhaustive account here. However, having been as critical of Allsup's views as I have, I feel obliged to sketch what a constructive alternative might look like.

I believe that instead of dichotomous open/closed texts (in which a fetish is made of the former and a straw man of the latter), music and music education and music education philosophy are more fruitfully understood as diverse human practices (or, more precisely, as constellations of practices): as ethically guided pursuits that seek to navigate a precarious passage between the Scylla and Charybdis of freedom and responsibility - both of which are potentially desirable, and both of which are dangerous if pursued in excess. This dialectic is something to which Allsup acknowledges the late Bennett Reimer having drawn his attention (126), suggesting that freedom/structure would be more useful than a rigid, open/closed dichotomy. ${ }^{9}$ Unfortunately, Allsup does not appear to have taken Reimer's sage advice to heart. While I will not claim that Reimer's views coincide with mine (in many respects they do not), his point about what I prefer to call the freedom-responsibility dialectic ${ }^{10}$ is highly compatible with practice theory as I understand it; and it constitutes advice that, had it been taken to heart, would have served Allsup well. ${ }^{11}$

The views I advance here align closely with what have been called "praxial" orientations. ${ }^{12}$ However, I have chosen in recent years to use the term practice, in an effort to advance philosophical discussion without becoming mired in the distortions and misrepresentations detractors (Allsup regrettably among them) have sought to attach to the idea of "praxis." The term "practice" has disadvantages of its own, to be sure, not least its widespread casual use in senses contrary to the neo-Aristotelian understanding I advocate. But here is a thumbnail sketch of what I mean: A practice, as I intend the term, is a fundamentally social, cooperative mode of human action that takes its guidance from distinctly ethical dispositions-from understandings, in other words, of what kinds of activities and personal attributes support or undermine the human benefits the practice exists to deliver.

Bowman, Wayne. 2017. "Open Philosophy" or Down the Rabbit Hole? Action, Criticism, and Theory for Music Education 16 (1): 10-37. doi:10.22176/act16.1.10 
Each part of this definition is crucial (I will, in due course, introduce definitions by others who are far more articulate than I), but a few concerns warrant particular attention. First, practices are not things or entities-not forms or texts. Practices consist in human "doings." That said, humans do many things that are not practices. Unlike individual behavior, for instance, practices are cooperative and collective modes of human action; and unlike mere activity, "busy-ness," random endeavors, or mere routines, the "actions" that comprise practices are intentional-directed mindfully toward the attainment of certain ends. These ends, "goods," or intended outcomes constitute the practice's raisons d'être. Importantly, a practice's "goods" may be of two kinds: those that serve to protect, enrich, or extend it, benefitting all who are appropriately engaged (these are a practice's internal goods); and those that benefit individuals or institutions to the potential detriment of other practitioners (these are external goods). ${ }^{13}$ Now the most important point, one that is crucial to the distinction between practices and patterns of activity that are not practices: Because the ends a practice exists to serve (Francis Sprarshott called these the practice's "nerve") are cooperatively determined, they are never set in stone. They are never what Allsup would probably call "statutory" or "closed." Instead, they are ever subject to negotiation and renegotiation; so, too, is the appropriate balance between a practice's internal and external goods-the goods that nurture and enrich the practice and those that may either support or undermine it. Crucial to this understanding is that a practice, unlike other modes of human activity, is guided by the ethical dispositions of its practitioners-not by Laws, or by Masters, or by obdurate rules.

From this it follows that there may be (indeed, there are) multiple musical practices, each with distinctive sets of provisional convictions as to what constitutes musicality, and each with distinctive ethical guidance systems. Musical practices differ in terms of the norms they embrace, and also in terms of the degree of latitude deemed musically (ethically) appropriate for deviation from these norms. There are, however, two extreme conditions that acutely undermine a practice's viability: conditions of complete "openness" and of utter "closure." A practice that is wholly open-with no sense of responsibility to the goods to which it is devoted, without recognition of the kinds of what actions are appropriate or inappropriate, or with no sense of the values and traditions it should embody-is simply not a practice. It is just something people happen to do, where any doing

Bowman, Wayne. 2017. "Open Philosophy" or Down the Rabbit Hole? Action, Criticism, and Theory for Music Education 16 (1): 10-37. doi:10.22176/act16.1.10 
counts. Conversely, a practice in which all questions about permissible latitude have been definitively resolved-in which all questions have been replaced by answers, rules, and provisions for their enforcement-is no longer a living practice, but a dead one. Practices are intricate, living processes, kept alive in the ethically guided actions of their practitioners. They are also vulnerable; and where the ethical discernment of a practice's participants no longer matters, either because of indifference to the ends to which it once owed its existence ("anything goes" or "openness"), or because ethical discernment and responsibility have been replaced by standardization, rules, or technical guidance systems, the practice ceases to exist. Or, more precisely, it exists as something or some process that is not a practice: a routine, for instance, a method, or a technique.

This understanding is crucial because practices are threatened most seriously in situations where practitioners fail to recognize that practices are sustained by their service to internal goods (believing their actions to be utterly "free"), or in situations where they have relinquished their freedom in the interest of consistency, standardization, or "efficiency" (where their freedom is no longer deemed relevant to successful action). At the heart of practices is "practical knowledge," a highly valuable cognitive resource that manifests itself in ethically guided know-how that is practice specific; a cognitive resource that is threatened whenever and wherever practitioners no longer recognize and honor the distinctive nature of the practice at hand or its ethical guidance system.

Some musical (and other) practices endorse more individual freedom, while others are more restrictive. Different practices embody different degrees of personal autonomy and interpretive latitude. However, no practice, if it is indeed a practice, embraces freedom or openness to the utter exclusion of ethical responsibility. And conversely, no living practice, if indeed it remains an actual living practice, relinquishes concern about interpretive latitude to "technical rationality"-to rules, formulas, or the approaches to art-making Allsup calls statutory. Practices and practical knowledge are seriously threatened in situations of absolute freedom and absolute constraint.

I hope this begins to make clear why I find Allsup's accounts of "openness" so deeply troubling. Open encounters and open forms may well involve "[breaks] from fixed categories in art and life" (3), but musical practices are not fixed categories. They are practices, embedded in human action, guided by ethical

Bowman, Wayne. 2017. "Open Philosophy" or Down the Rabbit Hole? Action, Criticism, and Theory for Music Education 16 (1): 10-37. doi:10.22176/act16.1.10 
discernment, and fueled by ongoing give-and-take as to what the central goods of the practice are. The "Laws" against which Allsup rails are characteristic not of musical practices but of their skeletal remains.

There is at least one further point to be made in light of the understanding of practice I proffer here. Practices are things people pursue cooperatively, processes in which they engage together. They are, in other words, fundamentally and inextricably social. Thus, when Allsup urges us to teach the "whole child," and to gauge the success of education "not merely against musical consequences, musical 'goods', or musical outcomes alone" (24), he is deposing another straw man. His claim that music education should be "human-specific, not practice-specific" (24) seriously misconstrues what is meant by "practice." The problem Allsup describes is problematic, in other words, only if one defines music (there's that pesky concern about definitions again) as an entity that is somehow separable from human action, values, and ethical discernment. This state of affairs, one that Kivy once described as "music alone," names an impossibility from the perspective of practice theory; 14 and that is because the ethical guidance from which all genuine practices take their direction involves not just inter-sonic relationships, not just abstractions, but actions taken by practitioners seeking to do the right thing, in the right way, to the right extent, in the right context, with the right collaborators, etc. Musical practices do not consist in pleasing patterns of sound but in patterns of human action from which a "whole person" cannot be extracted. That too, is among the crucial realizations we stand to lose when we regard music as a thing or as an entity (a "form") rather than as an ethically guided mode of human action. Christopher Small once wrote, "There is no such thing as music" (Small 1998, 2). Advocates of practice theory agree enthusiastically and have difficulty understanding what might possibly be meant by phrases like "musical outcomes alone."

In short: Musical and educational practices (and, as I will argue below, philosophical practices as well) are, as practices, necessarily plural and fluid. They are ethically guided and ever being renewed and extended. A practice is a living human process. Radical, anything-goes novelty and the utter absence of innovation are conditions under which no practice can survive.

Because ethical guidance figures centrally in the accounts of practice (or praxis) I advocate here, I must stress that by "ethical" I do not mean "moral."

Bowman, Wayne. 2017. "Open Philosophy" or Down the Rabbit Hole? Action, Criticism, and Theory for Music Education 16 (1): 10-37. doi:10.22176/act16.1.10 
Because this is also a distinction I have explored in detail elsewhere (Bowman 2016, for example), I will not rehearse those arguments in detail here. It is, however, a distinction crucial to an adequate understanding of practice theory. It is also one that is important to stress lest readers mistakenly assume my emphasis on the ethical nature of practices parallels Allsup's occasional appeals to the "morality" of openness. When Allsup asserts that the "more perilous," open world he endorses "is moral .... [or at least] has a moral sense-a quality of travel, growth, and adventure..." (128), I'm afraid I haven't the slightest idea what he is talking about. Talk of "morality" fell out of philosophical favor in the 1980s, and has been widely replaced by "ethics" (see Higgins [2011, 2012] for illuminating accounts of the distinction). Unfortunately, Allsup treats morality and ethics as if they were synonymous. The fundamental mistake of modern moral philosophy has been its failure to recognize that the obligations that are morality's stock in trade are, as Williams (1985) has shown, "just one type of ethical consideration" (196). In its myopic focus on what it is right to do, modern moral philosophy has acutely neglected the broader, ethical issue, what it is good to be. As Charles Taylor (1989) has explained, moral theory narrows the focus of ethical deliberation to obligations, a focus detrimental to more fundamental ethical concern about the nature of the good life.

As I draw this section to a close, I quote at length two thoughtful, detailed, and meticulously crafted definitions of practice that warrant careful study because they extend in important ways the brief sketch I offered earlier.

A practice, relates Higgins (2012), elaborating on the key provisions of MacIntyre's classic definition (1984/2007), is a

socially rooted, complex, coherent, and cooperative activity that grows over time into its own ethical world.... What distinguishes a practice from other activities is the way it becomes home to a distinctive set of answers to the basic ethical questions: What is it excellent to achieve or become? Through participating in a practice, we learn how to appreciate and realize the 'internal goods' of the practice, internal because their value can only be articulated in the terms of the practice, can only be appreciated by those who have apprenticed themselves to it, and cannot be cashed out in instrumental terms. (224)

Joseph Dunne (2005) puts it this way: A practice is a

coherent, complex set of activities that has evolved cooperatively and cumulatively over time, that is alive in the community who are its practitioners, and

Bowman, Wayne. 2017. "Open Philosophy" or Down the Rabbit Hole? Action, Criticism, and Theory for Music Education 16 (1): 10-37. doi:10.22176/act16.1.10 
that remains alive only so long as they remain committed to sustaining-and creatively developing and extending-its internal goods and its proper standards of excellence. (368, emphasis mine)

These are sobering claims, it seems to me: A practice is alive and remains alive only so long as its practitioners remain committed to sustaining, developing, and extending its own proper standards of excellence. If music consists in practices, then, failures to think carefully, deeply, and cooperatively about what a given musical practice's proper standards of excellence may be pose significant threats to its integrity and, ultimately, to its very existence as a vital, living, process. Caution is therefore warranted toward an orientation that construes musical encounters as "texts" or "forms" and sees their value solely in terms of 'openness' and service to democracy. Such thinking poses a real threat to the continued existence of what I would argue are among our most valuable cognitive/ethical resources-engagements through which we confront the fundamental question: What kind of person is it good to be? This is no minor, technical claim because it follows, I submit, that practices are where we learn some of our most profound, vivid, and durable lessons about what it means to think and act ethically.

While it is not possible to do them justice here, several concluding observations warrant particular emphasis. First, practices (again: whether musical, instructional, or philosophical) are not purely conservative affairs, exclusively concerned with tradition and its preservation. They are equally concerned with progressive affairs like extension, revision, innovation, and improvement. They are concerned with right action, where "rightness" is multidimensional and highly contextual. They are indeed committed to protecting the aims and ends for which the practice exists, but these are always (in living practices) being clarified, modified, adjusted, and elaborated. Practices are intricate and fluid affairs in which practitioners are necessarily engaged in efforts both to protect and to enrich the goods to which their collective efforts are devoted. They are neither "closed" nor are they utterly "open." As I hope I have shown, those extremes are precisely the conditions under which practices cease to be.

Secondly, while successful apprenticeship is crucial to the integrity and ongoing vitality of a practice, apprenticeship is not a coercive, indoctrinative affair, consisting of Laws enforced by doctrinaire Masters, and depriving inductees of their freedom. That is in no small part because to enter into a practice is to 
become a participant in passionate, dynamic, ongoing discussions about the goods the practice exists to serve and how best to serve them-discussions that are never (as long the practice retains its integrity) closed in the way Allsup insists they are. There is a sense in which the practice constructs the practitioner-because, clearly, practices are not affairs in which anything goes, everything is beautiful, and expertise is whatever anyone might wish it to be. In this highly qualified sense, practices are exclusive. Just as one hopes the practice of surgery is not inclusive of just anyone who happens to show up, practices exist to achieve certain goods and to guard against encroachments by rivals-in particular those that mistake the practice's external goods (pay, prestige, fame, and so forth) for those internal to the practice (whose attainment benefits the practice and all its practitioners). While there is an important sense in which the practice constructs the practitioner, there is another sense, at least as strong, in which practitioners are always constructing the practice. As Dunne (2005) shrewdly observes, "the horizon of [the practitioner's] judgement is always set by the proper ends, goods and standards of the practice and is always at least potentially directed towards, and testable by, other practitioners set within the same horizon that establishes the practice as a collaborative and communal space" (382). Practices are not governed by laws; nor are they utterly idiosyncratic, individual affairs. They are at once constructed by and construct practitioners. Again: They are neither absolutely free, nor are they closed. Accordingly, musical instruction that seeks utter openness would appear to eschew any affiliation with extant musical practice.

And finally, although at first gloss this may seem to contradict what I have been saying here, it seems clear that music is not "a" practice. It consists, rather, in a constellation of practices, some of which converge and overlap with others in important ways, while others diverge just as strongly. The same can be said, I suspect, for practices that are musically instructional. The musical and instructional approaches Allsup advocates, then, may well be defensible and deserving of the recognition for which he argues. But they can, and, I would argue, should exist comfortably alongside others. The validity of his approach does not require that all other contenders be relegated to a "closed text" slag heap. Among the primary concerns of those who have sought to advance "praxial" accounts of music and music education has been the articulation of a pluralistic vision that counters the mistakes of universalism (read: aesthetic education) on the one 
hand while avoiding the irresponsible excesses of relativism on the other. I submit that what I am calling practice theory lends itself well to these concerns.

\section{The Goods of Philosophical Practice}

Implicit in much of what I have said to this point is a conviction that music education philosophy is, like music, and like musical instruction, a practice. If that is the case, it must be acknowledged that what constitutes its "nerve"-the human ends it exists to serve-is neither set in stone nor are the standards by which its success is gauged entirely up for grabs. The idea that "all should have a say in what counts as good or right" (Allsup, 107) is no more valid for philosophy than it is for music-although I hope it is clear this does not mean I believe such conversations should be the exclusive domain of philosopher kings.

"An open philosophy of music education," states Allsup, "is one that must continuously seek renewal; it must operate in a way that is ongoing and provisional" (134). This is actually a fairly good characterization of philosophical pragmatism, with which practice theory is closely aligned. However, commitments to "renewal" without improvement or progress spell potential trouble, and these are quite often what advocates of postmodernism deliver. ${ }^{15}$ We need standards-however provisional, and however subject to revision-that help us separate the philosophical wheat from the chaff, that enable us to differentiate between potentially fruitful philosophical practice and claims that are arbitrary, irresponsible, or just plain silly. On this crucial point, pragmatism and postmodernism diverge significantly.

I have already advanced a number of arguments that highlight what I take to be the goods of philosophical practice: commitment to clarity, definition of terms, clear practical application, and so forth. Consistency is another philosophical virtue, ${ }^{16}$ I believe, and to be consistent with my claims about the nature of practices I must acknowledge that other convictions and other approaches may exist. However, whether they are advanced responsibly, and by standards embraced by philosophical practitioners are essential considerations. Again, not just anything counts as philosophy. Where fundamental differences exist as to what constitute the virtues of philosophical practice, those differences need to be rendered explicit and discussed in ways that are congruent with standards accepted by other

Bowman, Wayne. 2017. "Open Philosophy" or Down the Rabbit Hole? Action, Criticism, and Theory for Music Education 16 (1): 10-37. doi:10.22176/act16.1.10 
practitioners. Successful philosophical practice is not a shouting match or a function of one's access to means of dissemination. Philosophical virtues are no more arbitrary than musical or instructional virtues. Neither, of course, are they set in stone.

With these qualifications in mind, I will make a few additional claims about responsible philosophical practice-claims that may be challenged, but if so, on grounds that are recognizably philosophical. The first of these is that philosophical practice is, like musical and instructional practices, a socially rooted, cooperative endeavor that thrives where practitioners work collaboratively in an effort to preserve and creatively extend the goods for which the practice most fundamentally exists. If this is so, sound philosophical practice acknowledges, builds upon, and seeks to improve previous philosophical practice. Central to philosophical pragmatism and to the accounts of creativity and discovery aligned with it is the view that meaningful practical (if philosophy is a practice, it must be practical!17) accomplishments involve fruitful extensions of extant practice. They do not work in utter isolation or seek the wholesale replacement of the practice from which they emerge, or to which they claim to belong. They exhibit, on some level, continuity with the practices, ideas, or hypotheses they purport to modify. Judgments as to whether this has occurred are highly contextual, and are grounded in the practitioner's broad familiarity with the subject matter, aims, and criteria appropriate to the practice at hand. This parallels scientific practice in important ways. As Callaway (2007) explains, "In initial evaluation of hypotheses proposed, we must start from a detailed and systematic account of past accomplishments in the field, together with the outstanding anomalies and problems. It is out of this tension that the properly disciplined and genuinely creative imagination arises" (13). Crucial to the success of such important efforts is fair and accurate representation of claims being scrutinized. Where this happens, one's successes advance the practice at hand; where it fails, the practice can be drastically compromised.

While, as MacIntyre (1984/2007) has aptly observed, a living practice is "an historically extended, socially embodied argument precisely about the goods which constitute [it]" such that vital practices "embody continuities of conflict" (222), it is crucial to note his emphasis upon historical extension and social embodiment. His claim that such arguments are precisely about the goods constituting the practice is equally compelling. "To become a practitioner," I have urged

Bowman, Wayne. 2017. "Open Philosophy" or Down the Rabbit Hole? Action, Criticism, and Theory for Music Education 16 (1): 10-37. doi:10.22176/act16.1.10 
(Bowman 2015), "is to enter into particular kinds of relationships with contemporary and past practitioners, relationships rooted in shared ethical commitments to sustaining, creatively developing, and extending the practice's proper endswhile the precise nature of those proper ends remains an open question" (51). Practices (and philosophical practice is the case in point here) are complex, cooperative modes of action. Accordingly, "Practitioners can resist the corrosive and erosive influences of things that subvert a practice only where there is clarity about its nature" (51).

I raise these points because I am concerned Allsup has not demonstrated consistently the commitment to advancing the ends of philosophical practice discussed here. Indeed, he declares, astonishingly: "I want to embrace the beautiful failure of language" (118). I am also concerned that he has neglected or seriously misrepresented important philosophical-theoretical work that has been done in music education, work he might have used to build bridges instead of erecting walls.

As suggested above, both practice theory and the so-called praxialists have sought to honor pluralism and contest essentialism. Both of these are, one suspects, concerns Allsup may share. However, whereas practice theory seeks to pursue these ends in ways that avoid anything-goes relativism, Allsup's "openness" often appears to favor absolute autonomy: complete independence ("freedom”) from extant practices, seeking to step outside practice altogether. ${ }^{18}$ Instead of engaging with, refining, or extending work that has gone before-helping to move philosophical practice forward-he seems intent on constructing it anew, de novo. Here is how Frega and I discussed matters like these in the Oxford Handbook (a volume that does not appear in Allsup's bibliography):

Will suspicion toward canonicity and metanarratives-about the nature of music, education, music education, philosophy, and music education philosophy-require that [we] start anew with each new generation? Burbules [2000, 14-15] puts the challenge this way: "How [can] a discipline that is continually remaking itself ... respect the cumulative gains of sustained lines of inquiry, without discarding substantial bodies of scholarship as simply the outmoded musings of philosophical paradigms that have been transcended or surpassed[?]" Will each succeeding generation of theorist-practitioners become, in effect, "amnesic about their predecessors?" Or rather, will traditions of philosophical inquiry ... continue as "sustained conversations along diverse texts and perspectives, to which each is regarded as making a distinct contribution?" (Oxford Handbook, 507)

Bowman, Wayne. 2017. "Open Philosophy" or Down the Rabbit Hole? Action, Criticism, and Theory for Music Education 16 (1): 10-37. doi:10.22176/act16.1.10 
Elsewhere in the Oxford Handbook we sought to explain:

We have advocated openness, yet warned against its excesses; and we have emphasized the necessity for standards of philosophical practice, while stressing the need for these to be flexible, responsive, adaptive, and responsible. At issue, then, is not whether openness or robustness is inherently more important; rather, the question we should ask is which is more important for specified needs, more useful for the ends at hand. In a practice like music education such determinations must be made in light of practical problems and issues, and in light of the needs of those for whom the practice exists. (23)

Elsewhere (Bowman 2015), I have written at length on what appear to me to be the virtues of philosophical practice. I will not repeat here the nuanced arguments I tried to advance in that chapter, but a few lines seem particularly pertinent here:

Unlike mere opinion, philosophy carefully incorporates mutually accepted ways of testing the merits of competing views. Without these, belief systems become ideological turf wars in which victory is more important than truth and the victors are those who shout louder or are better able to harness institutional channels to disseminate their views. Responsible philosophical practice submits to analytical and discursive standards. The notion that all such standards are purely arbitrary and that, therefore, all philosophical perspectives are equally validthat anyone is entitled to his or her own "philosophy"-is not unlike the silly claim that everything is beautiful in its own way. This kind of anything-goes relativism is anathema to philosophical inquiry. (46)

Philosophy "seeks to identify confused thinking and action," we wrote in the Oxford Handbook, "making action more intelligent, more informed, and more congruent with responsibly held, defensible beliefs. The last thing we would want philosophy to do, then, is to compound confusion" (5).

\section{In (Yes) Closing}

In drawing this essay to a close, let us explore briefly a statement that encapsulates many of the assumptions framing Allsup's arguments. "I want to trespass predetermined borders," he writes, "to look beyond unifying references and unified standards of practice, beyond the kinds of statutory art-making that give rise to hierarchical displays of power ... and exclusionary practices that mark off some as musical and others as not” (107).

Bowman, Wayne. 2017. "Open Philosophy" or Down the Rabbit Hole? Action, Criticism, and Theory for Music Education 16 (1): 10-37. doi:10.22176/act16.1.10 
By all means, let us resist "predetermined borders." However, these are not what govern or guide musical practices. "Standards of practice" are neither unified nor are they as unifying as Allsup would have us believe. Indeed, one of the primary concerns of praxial orientations has been to show that standards of practice are negotiated, changeable, and changing: that they consist in habits that are intersubjectively established, ethically guided, and necessarily subject to modification when they stray too far from the ends they purport to serve. ${ }^{19}$ "Statutory art-making" is obviously undesirable. ${ }^{20}$ But who among us actually engages in such a thing or argues in its favor? Refuting a view no one holds or an action in which few actually engage may be emotionally satisfying but it accomplishes little, philosophically. It is equally clear that "hierarchical displays of power" are undesirable. They are, in fact, anathema to presentational musical practices and destructive of participatory musical practices. Troubling though the image of a conductor on a podium may be, however, it is not inevitably or unavoidably a display of power. Coordination and facilitation do not reduce to imposition or coercion, any more than delegation of decision-making is destructive of democracy. "Exclusionary practices"? All practices are exclusionary in some sense. A "practice" that excludes no one and in which everyone is deemed equally proficient regardless of background or experience-a "practice" in which everyone is deemed a qualified practitioner just in virtue of showing up-is simply not a practice. This goes to the heart of Allsup's claim to an "open philosophy," since it appears to favor musical (and philosophical?) undertakings in which anyone and everyone participates equally, without reference to conventions or guiding assumptions. Again, I am reluctant to call this a practice, for reasons I hope have been made clear here; but if it is held to constitute a practice (or, indeed, if "open philosophy" as described by Allsup warrants its claim to philosophical status) it is at most one among many and is, as such, answerable to the ethical concerns that constitute the nerve of the philosophical practice of which it claims to be a part.

Lastly, Allsup's complaint that "exclusionary practices ... mark off some [efforts] as musical and others as not." If all practices are at once exclusionary and inclusionary, this is simply a red herring: it misrepresents what practices actually do and how they work. Within a given practice, musical/unmusical distinctions amount to judgments that might alternatively be termed appropriate or inappropriate, more imaginative or less so-although one suspects Allsup might find 
these terms equally offensive. Regardless, such concerns are truly problematic only where one takes "music" to be a single, uniform undertaking in which the only differences that count are openness or closedness. If, on the other hand, music consists in diverse constellations of practices, and if musicality and musicianship can be manifest in a variety of ways, then a given effort may very well be judged more or less successful in light of the goods attending a particular musical practice without denying its musical status outright. ${ }^{21} \mathrm{I}$ suspect this is what is most often being done when judgments of "nonmusical" are proffered, and there is nothing necessarily odious about that. If Allsup is arguing that music is not a single practice, unified and uniform (I must say "if" because of his reluctance to define what he takes "music" to mean), then he should be welcomed to the praxial point of view. That view is precisely that different musical practices configure "musicianship" differently, and that these configurations are always being reconstructed, modified, renewed, extended, and improved upon by practitioners concerned to assure their respective practices best achieve their intended ends. If, on the other hand, Allsup's point is (as appears likely) that no valid distinctions can or should be drawn between actions that are musical and unmusical, then he is saying that everything is musical; and if everything is musical, nothing is, because words like "music" and "musicianship" no longer signify anything distinctive in the world. If this is philosophical, it is irresponsible philosophy; or perhaps, as I suggested earlier "open philosophy" is simply an oxymoron, indifferent as it often appears to be to the internal goods of philosophical practice.

I have written at much greater length here than I originally intended. I hope it is clear, though, that my reasons for doing so are altruistic, arising from sincere concerns about the ways we understand and engage in musical, music educational, and philosophical practices. The words and ideas we use to understand, shape, and guide our professional practices matter, and they matter a great deal. The points on which Randall Allsup and I differ are many, and they are substantial. However, this much I will grant: School music as it is currently configured and practiced-as it has been practiced for decades in North American public schools, and as it is being exported to and imitated in many other parts of the world-does not welcome divergent voices, encourage innovation, or nurture imagination. It does not encourage people to explore musical or instructional trajectories that depart from the main stream, or to pursue the kinds of tensions from which 
practices derive their dynamism and vitality. North American school music is far more conservative than educational practice in the other arts, ${ }^{22}$ a situation for which teacher training programs are extensively-though not solely-responsible. To make these points however, it is not necessary to divide the profession against itself, or to denigrate the instructional practices of those whose instructional aims diverge from those of the public school music classroom. That promotes intolerance that is every bit as unbecoming as the closed-mindedness of which Allsup is so critical.

\section{About the Author}

Dr. Bowman's academic career included positions at New York University, University of Toronto, Brandon University (Manitoba, Canada), and Mars Hill University (North Carolina). His instructional responsibilities ranged from applied low brasses to jazz band, from curricular studies to research and philosophy. His primary research interests involve philosophy of music and the philosophical exploration of issues in music education. His work is extensively informed by philosophical pragmatism, by critical theory, and by conceptions of music and music education as social practices. He is particularly concerned with music's sociopolitical power, music and social justice, and ethically informed understandings of musical practice.

\section{References}

Allsup, Randall E. 2016. Remixing the classroom: Toward an open philosophy of music education. Bloomington, IN: Indiana University Press.

Bowman, Wayne. 2006. The future of university music studies in Canada. Ecclectica (September). http://ecclectic.brandonu.ca/issues/2006/2>

Bowman, Wayne. 2014. The ethical significance of music-making. In Music Mark: The UK Association for Music Education. Issue 3 (Winter). musicmark.org.uk. Reprinted in Music Education Now https://jfin107. wordpress.com/scholarly-paper-the-ethical-significance-of-music-makingby-wayne-bowman/

Bowman, Wayne. 2015. The virtues of philosophical practice. In Music education: Navigating the future, edited by Clint Randles, 43-60. New York, NY: Routledge.

Bowman, Wayne. 2017. "Open Philosophy" or Down the Rabbit Hole? Action, Criticism, and Theory for Music Education 16 (1): 10-37. doi:10.22176/act16.1.10 
Bowman, Wayne. 2016. Artistry, ethics, and citizenship. In Artistic citizenship: artistry, social responsibility, and ethical praxis, edited by David Elliott, Marissa Silverman, and Wayne Bowman, 39-80. New York, NY: Oxford.

Bowman, Wayne, and Ana Lucia Frega. 2012. The Oxford handbook of philosophy in music education. New York, NY: Oxford.

Burbules, Nicholas C. 2000. Philosophy of education. In Routledge international companion to education, edited by Bob Moon, Sally Brown, and Miriam BenPeretz, 3-18. New York, NY: Routledge.

Callaway, H. G. 2007. Abduction, pragmatism, and the scientific imagination. https://www.researchgate.net/publication/264239585_AbductionPragmatis m_and_the_Scientific_Imagination

Dunne, Joseph. 2005. An intricate fabric: Understanding the rationality of practice. Pedagogy, Culture, and Society 13 (3): 367-89.

Higgins, Chris. 2011. The good life of teaching: An ethics of professional practice. Oxford, UK: Wiley-Blackwell.

Higgins, Chris. 2012. The impossible profession. In The Oxford handbook of philosophy in music education, edited by Wayne Bowman and Ana Lucia Frega, 213-30. New York, NY: Oxford.

Lewis, Michael. 2016. The undoing project: A friendship that changed our minds. New York, NY: W.W. Norton \& Company.

MacIntyre, Alistair. 1984/2007. After virtue. Notre Dame, IN: University of Notre Dame Press.

Reimer, Bennett. 2015. Response to Randall Allsup, "Music teacher quality and expertise." Philosophy of Music Education Review 23 (1): 108-112.

Small, Christopher. 1998. Musicking. Middletown, CT: Wesleyan University Press.

Taylor, Charles. 1989. Sources of the self: The making of the modern identity. Cambridge, MA: Harvard University Press.

Williams, Bernard. 1985. Ethics and the limits of philosophy. Cambridge, MA: Harvard University Press.

Bowman, Wayne. 2017. "Open Philosophy" or Down the Rabbit Hole? Action, Criticism, and Theory for Music Education 16 (1): 10-37. doi:10.22176/act16.1.10 


\section{Notes}

${ }^{1}$ Hereafter referenced as "Oxford Handbook."

2 Except where otherwise indicated, all page references in this essay are to Allsup (2016).

3 This making/doing binary is apparently intended as a dig at Elliott's claim that music is something people "do"-an assertion taken out of context so it can be easily discredited: another straw man.

4 Outgroup homogeneity is a prominent mechanism in the psychology of prejudice. Lewis (2016) makes a related point: "A banana and an apple seem more similar than they otherwise would because we've agreed to call them both fruit. Things are grouped together for a reason, but, once they are grouped, their grouping causes them to seem more like each other than they otherwise would. That is, the mere act of classification reinforces stereotypes. If you want to weaken some stereotype, eliminate the classification" (115). Conversely, I suggest, to strengthen a stereotype, stiffen the boundaries used create the classification: in this case, "open/closed."

5 Here is one of the many places in which it appears Allsup's condemnations of apprenticeship are not restricted to its use in school music instruction but are intended universally: wherever and whenever apprenticeship occurs. Allsup's reference to "sharing" here also seems rather disingenuous, given the absence of discernible common ground between his open-text educator and the invariably closed nature of apprenticeship.

${ }^{6}$ An important point whose adequate treatment would have lengthened considerably what is already a long essay: Allsup often seems to imply that musical traditions, practices, and standards are inappropriate in public school education. An alternative view (one often advanced by praxial theorists) is that preparing students to be active participants in real-life (out of school) musical practices is in fact an honorable educational goal. At issue, of course, is whether current instructional practices cater to insular "school music" activities rather than to real-life (out of school) practices.

7 I hasten to add, however, that there are numerous instances in which his criticisms are directed at all musical and instructional practice, everywhere. In other words, I make his orientation sound clearer here than it actually is.

8 This is not to say that the master-apprentice approach cannot or should not be modified to address clear abuses. Nor is it to deny that such abuses occur. How-

Bowman, Wayne. 2017. "Open Philosophy" or Down the Rabbit Hole? Action, Criticism, and Theory for Music Education 16 (1): 10-37. doi:10.22176/act16.1.10 
ever, Allsup does not argue for modification: he argues for elimination. Interestingly, he has little if any concern that his "open" approach might be abused or pursued in excess.

9 Key to the creation of such false dichotomies, incidentally, is what philosophers call the fallacy of the excluded middle.

${ }^{10}$ I much prefer "responsibility" to Reimer's "structure," because structure represents but one dimension of artistic responsibility. Both, however, implicate an underlying continuum that is absent from Allsup's account.

${ }^{11}$ In Reimer's (2015) words: "While freedom without structure is empty, structure without freedom is meaningless. Each depends upon the other to achieve... significance" (110-111). "If [classical musics] were not open in their vitalities and possibilities," he continues, "we would never need to, or want to, perform or listen to them more than once. What would be the point?"

12 Just how closely my accounts align with those of other avowed "praxialists" is a matter some may well wish to raise. I don't see that as particularly problematic, however, since praxial orientations are plural, not monolithic (this being one of the more frequent misunderstandings promulgated within music education circles).

${ }^{13}$ External goods, note, still warrant recognition as "goods." They become detrimental only when pursued in excess - when their pursuit usurps the place of the goods internal to the practice. While external goods benefit primarily individuals and institutions, they clearly figure among a practice's attractions. For a more nuanced accounting of internal and external goods, see MacIntyre (1984/2007) and Dunne (2005).

${ }_{14}$ This is not unlike the sound created by the proverbial tree falling in a forest with no one there to hear it.

15 Parenthetically, it strikes me that Roland Barthes and John Dewey, on whom Allsup draws extensively, make for rather strange philosophical bedfellows. Their philosophical trajectories are often at odds with each other.

16 The list of "philosophical virtues" I developed in Bowman $(2015,56)$ includes: Rigor, Clarity, Practicality, Sense of Relevant Tradition, Fairness, Courage, Humility, Respect, Responsiveness, Consistency, Interdependence, and Selfreliance. The existence of tensions among these figures centrally in the way I have sought to define "virtue."

Bowman, Wayne. 2017. "Open Philosophy" or Down the Rabbit Hole? Action, Criticism, and Theory for Music Education 16 (1): 10-37. doi:10.22176/act16.1.10 
${ }^{17}$ I hasten to emphasize that "practical" does NOT mean "practicable."

18 The reader might well note the efforts by John Cage and others to claim practical territory outside extant practice. I think it safe to say that the success of such efforts remains very much an open question. Those who have struggled to free themselves from the constraints of the (oppressive?) tonal music system have encountered similarly mixed results, even though their efforts were not as radically divergent as Allsup's "open” stance.

19 This is what philosophical pragmatism describes as the habit of changing habits.

${ }^{20}$ In fact, I suspect the phrase is an oxymoron.

${ }^{21}$ And this is simply because there are different kinds of musicianship.

${ }^{22}$ When inviting contributors to a journal project I edited some years ago (Bowman 2006), I commented, "In an era of rupture variously characterized as postmodern, poststructural, postcolonial, and postclassical, what often appears most striking about university music schools is their uninterrupted continuity with their pasts." Relatively little has changed since then.

Bowman, Wayne. 2017. "Open Philosophy" or Down the Rabbit Hole? Action, Criticism, and Theory for Music Education 16 (1): 10-37. doi:10.22176/act16.1.10 